\title{
Socio-demographic correlates of substance use disorder patients seeking de-addiction services in Kashmir India -A cross sectional study
}

\author{
Nazima Bashir, Ajaz Ahmad Sheikh, Sufoora Bilques and Muhammad Mudasir Firdosi
}

\begin{abstract}
Background: Kashmir valley is thought to be one of the hardest hit places with drug use and the scenario worsened by the prevailing turmoil. The present study was undertaken to find the epidemiological profile and pattern of drug use in patients seeking treatment at De-addiction Centres in Srinagar India.

Methods: The present cross sectional study, was conducted at two Drug De-addiction and treatment Centers in Srinagar. Total of 125 Substance Use Disorder Patients were interviewed by using pretested semi-structured proforma, emphasizing on socio-demographic profile and reasons for starting use of substance.

Results: Majority (50.4\%) of patients belonged to young and productive age group. Most of the patients started taking substances in the age group of 10-19 years and more so in case of nicotine (76.8\%), volatile substances (76.9\%) and cannabis $(70.5 \%)$. Besides nicotine (89.6\%), the most common substances used were cannabis $(48.8 \%)$, codeine $(48 \%)$, propoxyphene $(37.6 \%)$, alcohol $(36.8 \%)$ and benzodiazepines (36\%). Peer pressure was the most common $(72.8 \%)$ reason for starting the use of substance.

Conclusion: There is need for further studies to find the community prevalence of drug use. The service provision is very limited restricted to the capital city and none in the rural areas. There is a worrying trend of early age of initiation with adverse consequences including dropping out of school. The control of prescription drug use is another major issue which needs to be addressed. It is also worrying that female drug users are not able to seek help due to lack of appropriate facilities.

Keywords: Addiction, drug abuse, treatment, Kashmir, conflict
\end{abstract}

\section{Introduction}

Drug abuse is a universal phenomenon and people have always sought mood or perception altering substances. Similarly the attitude of people towards addiction varies depending upon various factors and can come across as prohibition and condemnation to tolerance and treatment ${ }^{1}$. The United Nations Narcotics Bureau describes drug abuse as the worse epidemic in the global history ${ }^{2}$.India like rest of the world has huge drug problem. Located between two prominent drug producing hubs in the world, i.e. Golden Triangle (Burma, Laos and Thailand) and Golden Crescent (Iran, Afghanistan and Pakistan), India acts as a natural transit zone and thus faces a major problem of drug trafficking. Similarly the geographic location of Jammu and Kashmir is such that the transit of drugs is easily possible across the state. In addition the prevailing turmoil is claimed to have worsened the drug abuse problem alongside an unusual increase in other psychiatric disorders in Kashmir ${ }^{3}$.

There are not many studies about drug use from Kashmir and hardly any about the actual community prevalence. In addition, it is difficult to conduct a study in a community affected by drug abuse due to stigma associated with drug addiction.
Furthermore people hesitate to volunteer information due to laws prohibiting sale and purchase of such substances and risk of being criminally charged. In view of this difficulty the present study was conducted on the treatment seeking patients at the Drug De-addiction Centers. The present study was aimed at highlighting the epidemiological profile and pattern of drug use in Kashmir Valley.

\section{Material and Methods}

This cross-sectional study was undertaken at two Drug Deaddiction Treatment Centers (Government Psychiatric Disease Hospital and Police Hospital, Srinagar). Government Psychiatric Disease Hospital is the only psychiatric hospital in the Kashmir valley that also provides treatment for substance use disorder patients. The De-addiction center at the Police Hospital is run by Police Department in the capital city Srinagar. Both these centres have a huge catchment area comprising all districts of the valley, due to lack of such services outside the capital city, thus reflecting the community scenario to a greater extent. 
Table 1: Socio-demographic profile

\begin{tabular}{|c|c|c|c|}
\hline & & $\mathrm{N}$ & $\%$ \\
\hline \multirow[t]{5}{*}{ Age (years) } & 10 to 19 & 20 & 16.0 \\
\hline & 20 to 29 & 63 & 50.4 \\
\hline & 30 to 39 & 27 & 21.6 \\
\hline & 40 to 49 & 12 & 9.6 \\
\hline & $\geq 50$ & 3 & 2.4 \\
\hline Gender & Male & 125 & 100.0 \\
\hline \multirow[t]{3}{*}{ Religion } & Islam & 120 & 96.0 \\
\hline & Sikh & 3 & 2.4 \\
\hline & Hindu & 2 & 1.6 \\
\hline \multirow[t]{2}{*}{ Residence } & Urban & 56 & 44.8 \\
\hline & Rural & 69 & 55.2 \\
\hline \multirow[t]{3}{*}{ Marital Status } & Unmarried & 92 & 73.6 \\
\hline & Currently Married & 27 & 21.6 \\
\hline & Separated/Divorced & 6 & 4.8 \\
\hline \multirow[t]{3}{*}{ Education } & Illiterate & 5 & 4.0 \\
\hline & $</=$ high school & 71 & 56.8 \\
\hline & $>$ high school & 49 & 39.2 \\
\hline \multirow[t]{4}{*}{ Occupation } & Unemployed & 21 & 16.8 \\
\hline & Student & 25 & 20.0 \\
\hline & Government Job & 16 & 12.8 \\
\hline & Self employed & 63 & 50.4 \\
\hline \multirow[t]{2}{*}{ Type of family } & Joint & 36 & 28.8 \\
\hline & Nuclear & 89 & 71.2 \\
\hline \multirow[t]{5}{*}{ Socio-economic status } & Class I & 67 & 53.6 \\
\hline & Class II & 36 & 28.8 \\
\hline & Class III & 18 & 14.4 \\
\hline & Class IV & 3 & 2.4 \\
\hline & Class V & 1 & 0.8 \\
\hline
\end{tabular}

The study was conducted for a period of one year from July 2010 to June 2011. Substance Use Disorder Patients were diagnosed as per the Diagnostic and Statistical Manual-IV (DSM IV 2004) criteria ${ }^{4}$. Following informed consent, a total of 125 patients were included in the study. In case of minors ( $<18$ years of age), the consent was obtained from the guardian. Information was collected regarding the age, sex, residence, religion, marital status, educational status, history of school dropout, occupation and type of family, reasons for starting the substance of abuse, type of the substance abused, and age of initiation. The socio-economic status of the patients was evaluated by using the modified Prasad's scale for the year 2010 , based on per capita income per month ${ }^{5}$.

Results

A total of 125 Substance Use Disorder patients were studied and all were males. The majority of the patients $(50.4 \%)$ were in the age group of 20-29 years and most (73.6\%) were unmarried. Most of the patients were Muslims (96\%). There was nearly an equal urban to rural ratio. Most of the patients had completed their educationup to high school level or higher. There was a high rate of school dropouts $(41.7 \%)$ and among those, substance use being common reason (46\%) for school dropout. $71.2 \%$ belonged to nuclear families. Most of the patients $(53.6 \%)$ belonged to socio-economic class I as per Prasad's scale [Table 1]. Majority of the patients started taking substances in the age group of 10-19 years [Table 2]. Besides nicotine $(89.6 \%)$, the most common substances used were cannabis $(48.8 \%)$, codeine (48\%), propoxyphene $(37.6 \%)$, alcohol (36.8\%) and benzodiazepines (36\%) [Table3].

Table 2: Age at onset of initiation of Substance use by the patients seeking treatment for Substance Use disorder

\begin{tabular}{|l|l|l|l|l|l|l|}
\hline \multirow{2}{*}{ Substance } & \multicolumn{2}{|l|}{$<10$ years } & \multicolumn{2}{l|}{10 to 19 years } & \multicolumn{2}{l|}{$>19$ years } \\
\cline { 2 - 8 } & $\mathrm{N}$ & $\%$ & $\mathrm{~N}$ & $\%$ & $\mathrm{n}$ & $\%$ \\
\hline Nicotine & 11 & 9.8 & 86 & 76.8 & 15 & 13.4 \\
\hline Volatile Solvents & 0 & 0 & 10 & 76.9 & 3 & 23.1 \\
\hline Cannabis & 0 & 0 & 43 & 70.5 & 18 & 29.5 \\
\hline Codeine & 0 & 0 & 33 & 55 & 27 & 45 \\
\hline Propoxyphene & 0 & 0 & 24 & 51.1 & 23 & 48.9 \\
\hline Benzodiazepines & 0 & 0 & 20 & 44.4 & 25 & 55.6 \\
\hline Alcohol & 0 & 0 & 19 & 41.3 & 27 & 58.7 \\
\hline
\end{tabular}

Table 3: Type of substance used by the patients seeking treatment for Substance Use disorder*

\begin{tabular}{|l|l|l|}
\hline Substance & $\mathrm{N}$ & $\%$ \\
\hline Nicotine & 112 & 89.6 \\
\hline Cannabis & 61 & 48.8 \\
\hline Codeine & 60 & 48.0 \\
\hline Propoxyphene & 47 & 37.6 \\
\hline Alcohol & 46 & 36.8 \\
\hline Benzodiazepines & 45 & 36.0 \\
\hline Volatile substances/inhalant** & 13 & 10.4 \\
\hline Others*** & 23 & 18.4 \\
\hline
\end{tabular}

*multiple responses

** petrol, correction fluid, paint thinners, nail polish remover, 
hair sprays, dry cleaning fluids, adhesives, varnishes and deodorants

${ }^{* * *}$ cocaine, heroin, raw opium, guthka, lysergic acid diethylamide, dexamethasone, psilocybin, methylene di-oxy methamphetamine, snake bite

Table 4: Reason for starting the Substances among the patients seeking treatment for Substance Use disorder*

\begin{tabular}{|l|l|l|}
\hline Reason & N & $\%$ \\
\hline Peer Pressure & 91 & 72.8 \\
\hline Relief from psychological stress** & 49 & 39.2 \\
\hline Curiosity/Experimenting & 27 & 21.6 \\
\hline Fun/Pleasure Seeking & 13 & 10.4 \\
\hline Prescription medicine abuse ${ }^{* * *}$ & 12 & 9.6 \\
\hline Others & & \\
\hline
\end{tabular}

${ }^{*}$ multiple responses

** (family tragedy like death or disease in the family; history of arrests, torture in jail or death and disability in the family due to the prevailing turmoil; conflicts within family; loss of job or job dissatisfaction.

*** deliberate use of prescription medications for recreational purposes in order to achieve intoxicating or euphoric psychoactive effects, irrespective of prescription status ${ }^{* * * *}$ Family history, routine work or boredom, availability.

Peer pressure was the most common (72.8\%) reason for starting the use of substance [Table 4]. Majority of the patients started using substances in the age group of 10 to 19 years with $76.8 \%$ nicotine users, $76.9 \%$ volatile substances and $70.5 \%$ cannabis users among this group. The age of onset was higher ( $>19$ years) in case of benzodiazepines and alcohol.

\section{Discussion:}

Kashmir Valley has a population of over 6 million with around $70 \%$ people living in rural areas. ${ }^{6}$

There is almost no data available on the community prevalence of drug use in the valley. Population is predominantly Muslim with strong taboo on use of alcohol and other drugs. Interestingly, none of the patients in our sample are female which could be due to stigma associated with drug use and hence reluctance to seek treatment. The police drug addiction centre is locally in the police lines with heavy security which requires frisking, which may also prevent people, especially women, from seeking help. This does not mean females do not use drugs as evident from clinical practice and previous studies ${ }^{7}$. The sample is mostly comprised of a young age group of 20-29 years (50.4\%) followed by 30-39 years (21.6\%). Similar findings have been shown by the previous study conducted by Kadri et al. ${ }^{8}$ Another study on college going male students showed a prevalence of $37.5 \%$, suggesting young age at initiation and high prevalence in students. The results also show high school dropout rate due to drug use which could be due to the associated problems with drug use and negative impact on the overall quality of life and future prospects.

There is a minor rural predominance in the sample. This is consistent with findings of Drug Abuse Monitoring System India and other studies ${ }^{10-12}$, which reveal a nearly equal rural urban ratio with slight rural predominance. This could be due to the stigma associated with these centres and reluctance from local population to seek help due to fear of being identified and shamed.

$73.6 \%$ of the patients were unmarried with $4.8 \%$ separated or divorced. Similar results have been shown by Hasin DS et $\mathrm{al}^{13}$ and Martins SS et $\mathrm{al}^{14}$. The reason for predominant unmarried sample in our study could be due the higher number of younger age patients as compared to the current marriageable age.

The majority of the patients in our study were using cannabis, medicinal opioids (codeine and Propoxyphene), benzodiazepines and alcohol. One of the major reasons for high rate of opioids and benzodiazepines abuse in present study can be explained by over the counter sale of these drugs without the prescription from the doctor. This is a worrying trend as there is no proper drug control and it is easy to access any medication. Although there are only a few outlets selling alcohol in the whole of Kashmir, it is surprising how alcohol use is so common. It is speculated that current political turmoil may be responsible and people buy alcohol legally or illegally from army depots.

Most of the substance users had started taking drugs at the age of 10 to 19 years and more so in the case of nicotine, volatile substances and cannabis. Similar results have been found in the earlier studies. ${ }^{15}$ Nicotine was typically the first substance of abuse. Tobacco is often considered as a gateway to other drugs ${ }^{16}$.

The overall prevalence of volatile substance abuse in this study was $10.4 \%$ but significantly higher in the adolescent age group $(53.8 \%)$. About three fourths of the patients had started using volatile solvents in the age group of 10-19 years. Inhalant use has been identified as most prevalent form of substance abuse among adolescents by different studies ${ }^{17-18}$. The observation in present study could be explained by the easy accessibility, cheap price, faster onset of action, and a regular "high" with volatile substances like glues, paint thinners, nail polish removers, dry cleaning fluids, correction fluids, petrol, adhesives, varnishes, deodorants and hair sprays.

Peer pressure is the most common cause of initiation of drug use only to be followed by self-medication for psychological stress. Previous studies have shown similar results in relation to peer pressure and also the ongoing conflict situation to be responsible for increased drug use in the valley ${ }^{19-20}$. 


\section{Conclusion:}

There is a need for further studies to find the community prevalence of drug use. The service provision is very limited, restricted to the capital city and with none in the rural areas. There is a worrying trend of early age of initiation with adverse consequences including dropping out of school. The control of prescription drug use is another major issue which needs to be addressed. It is also worrying that female drug users are not able to seek help due to lack of appropriate facilities.

\section{Acknowledgements}

We are thankful to the staff of Government Psychiatric Disease Hospital and Police Hospital, Srinagar for their cooperation and help. We are also thankful to the patients who agreed to take part in our study.

Competing Interests

None declared

Author Details

NAZIMA BASHIR MD,Department of Community Medicine, Government Medical College Srinagar India. AJAZ AHMAD SHEIKH MD, University Hospitals, Case Medical Center, Cleveland, Ohio, USA . SUFOORA BILQUES MD, Department of Community Medicine, Government Medical College, Srinagar India. MUHAMMAD MUDASIR FIRDOSI MD , MRCPsych, South London and Maudsley NHS Foundation Trust London, United Kingdom. CORRESPONDENCE: Dr Muhammad M Firdosi, Department of Psychological Medicine, Guy's Hospital, 20 Newcomen Street, London SE1 1UL. Email: mudasirfirdosi@gmail.com

\section{References}

1. Semple David, Symth Roger. Oxford handbook of psychiatry. 2nd ed. New York: Oxford university press; 2009. p. 522.

2. The social impact of drug abuse; prepared by UNDCP as a position paper for the World Summit for Social Development (Copenhagen, 6-12 March 1995);

http://www.unodc.org/pdf/technical_series_1995-03-01_1.pdf

3. Margoob M A. The menace of drug abuse in Kashmir: trend, tradition or trauma? Srinagar: Valley Book House; 2008.

4. American Psychiatric Association Diagnostic and statistical manual of Mental Disorders, 4th ed (DSM-IV) 2004 Washington, DC.
5. Government of India, Ministry of Statistics and Program Implementation. http://mospi.nic.in/stat_act_t4.Htm Cited on 1 st November 2011.

6. Population Census 2011 : http://www.census2011.co.in/

7. Margoob MA et al. Changing sociodemographic and clinical profile of substance use disorder patients in Kashmir Valley. JK Practioner 2004;11(1):14-16

8. Kadri AM, Bhagyalaxmi A, Kedia Geeta. Socio-demographic characteristics of the substance abusers. Indian Journal of Community Medicine 2003 Apr.-June; 28(2):74-6.

9. Tufeel Baba et al. An epidemiological study on substance abuse among college students of north India (Kashmir Valley); International Journal of Medical Science and Public Health | 2013 | Vol 2 | Issue 3 , 562-567

10. Ray R, Mondal AB, Gupta K, et al. The extent, pattern and trends of drug abuse in India: National Survey. New Delhi. United Nations Office on Drugs and crimes and Ministry of Social Justice and Empowerment, Government of India 2002.

11. Mohammad Hussain et al. Characteristics of drug abusers admitted in drug abuse treatment centers at Peshawar, Pakistan. Gomal Journal of Medical Sciences 2004 July -Dec ; (2); 36-9.

12. Margoob M A et al. Use of TLC as broad spectrum screen for detection of drugs of abuse. JK Practioner 2004; 11(4):257-260.

13. Hasin DS, Stinson FS, Ogburn E, et al. Prevalence, correlates, psychiatric co morbidity, and treatment of DSM-IV alcohol abuse and dependence at Columbia University, New York, USA. Arch Gen Psychiatry 2007 Jul; 64(7):830-42.

14. Martins SS, Copersino ML, Soderstrom CA,et al. Sociodemographic characteristics associated with substance use status. J Addict Dis 2007; 26(2):53-62.

15. Lamptey J et al. Socio-demographic characteristics of abusers and compares some of the characteristics to randomly selected nonsubstance abusers. Ghana Med J 2005 Mar; 39(1):2-7.

16. Dhawan A, Jaain R, Kumar N. Proceeding of workshop on "Assessment of role of tobacco as a gateway substance and information available on evidence relating to tobacco, alcohol and other forms of substance abuse. AIIMS and WHO, New Delhi: 2004

17. Neumark Y, Delva J, Anthonh J C. The epidemiology of adolescent inhalant involvement. Arch Pediatr Adolesc Med 1998; 152: 781-786.

18. Wu L T, Ringwalt CL. Inhalent use and disorders among adults in the United States. Drug Alcohol Depend 2006; 85:1-11

19. Margoob MA, Dutta KS. Some peculiar features of cannabis abuse in Kashmir. Journal of Indian Society of Health Administrators 1992; 3:62-63.

20. Margoob MA, Dutta KS. Drug abuse in Kashmir: experience from a psychiatric disease hospital. Indian Journal of Psychiatry 1993; 35(3):163-165.

\section{(c) EY-NC-NO}

This article is licensed under a Creative Commons Attribution-NonCommercial-NoDerivatives 4.0 International License. 